Article

\title{
Sliding Mode Observer-Based Parameter Identification and Disturbance Compensation for Optimizing the Mode Predictive Control of PMSM
}

\author{
Meng Shao ${ }^{1,2}{ }^{\mathbb{D}}$, Yongting Deng ${ }^{1, *}$, Hongwen $\mathrm{Li}^{1}{ }^{1}$, Jing Liu ${ }^{1}$ and Qiang Fei ${ }^{1,2} \mathbb{D}$ \\ 1 Changchun Institute of Optics, Fine Mechanics and Physics, Chinese Academy of Sciences, \\ Changchun 130033, China; shaomeng0431@163.com (M.S.); lihongwen@ciomp.ac.cn (H.L.); \\ nuaaliujing@163.com (J.L.); feiqiang15@mails.ucas.ac.cn (Q.F.) \\ 2 University of Chinese Academy of Sciences, Beijing 100049, China \\ * Correspondence: dyt0612@163.com; Tel.: +86-15-764-309-709
}

Received: 15 April 2019; Accepted: 8 May 2019; Published: 15 May 2019

\begin{abstract}
This paper reports on the optimal speed control problem in permanent magnet synchronous motor (PMSM) systems. To improve the speed control performance of a PMSM system, a model predictive control (MPC) method is incorporated into the control design of the speed loop. The control performance of the conventional MPC for PMSM systems is destroyed because of system disturbances such as parameter mismatches and external disturbances. To implement the MPC method in practical applications and to improve its robustness, a compensated scheme with an extended sliding mode observer (ESMO) is proposed in this paper. Firstly, for observing if and when the system model is mismatched, the ESMO is regarded as an extended sliding mode parameter observer (ESMPO) to identify the main mechanical parameters. The accurately obtained mechanical parameters are then updated into the MPC model. In addition, to overcome the influence of external load disturbances on the system, the observer is regarded as an extended sliding mode disturbance observer (ESMDO) to observe the unknown disturbances and provide a feed-forward compensation item based on the estimated disturbances to the model predictive speed controller. The simulation and experimental results show that the proposed ESMO can accurately observe the mechanical parameters of the system. Moreover, the optimized MPC improves the dynamic response behavior and exhibits a satisfactory disturbance rejection performance.
\end{abstract}

Keywords: model predictive control; parameter identification; extended sliding mode observer; PMSM

\section{Introduction}

Permanent magnet synchronous motors (PMSMs) are widely used in many applications, including robots, electric vehicles, high-precision numerical control machine tools, and aircrafts, owing to their high precision, high moment of inertia ratio, high power density, high reliability, wide speed range, and excellent control performance [1,2].

However, the performance of the speed control system of PMSMs is poor under some operating conditions because of the inevitable uncertainties and external disturbances observed in practical applications [3]. To enhance the performance of the speed control system, many advanced control strategies have been proposed: Model predictive control (MPC), robust control [3,4], sliding mode control [3,5], adaptive control [6,7] observer-based control [8-10], fuzzy control, and neural network control $[7,11]$.

The MPC is an advanced control method widely used in industrial applications, owing to its simplicity of modeling, fast dynamic response, and satisfactory control performance [3]. It is an 
optimal control method, wherein a model of the controlled system is developed to forecast the future behavior of the system states and to determine a future control action sequence that minimizes the cost function [12]. Only the first value of the sequence is applied, and the method is implemented again for every sampling period [13]. The MPC can be categorized into transfer-function based, such as generalized predictive control, step response model based, such as dynamic matrix control, and state-space model based [14]. Moreover, the required optimization can be completed by solving a quadratic programming $(\mathrm{QP})$ problem. With the development of microprocessors, such as digital signal processors (DSPs) and field programmable gate arrays (FPGAs), the MPC method has been applied to PMSM control systems with a very short sampling period [15]. Given these advantages, some scholars have successfully employed the MPC method in PMSM control systems [16-20].

In PMSM control systems, the cascade-structure control strategy remains the most popular [12]. In the rotor flux orientation control method, the control structure comprises a speed loop and two current loops [15]. In this paper, a discrete state-space model is employed based on the mechanical motion equation of a PMSM system. A discrete model predictive controller (DMPC) is then incorporated in the speed loop, and an optimal control law is designed by minimizing the cost function. The cost function is composed of an item on the future speed tracking error and a penalization item on the incremental control action sequence.

However, in industrial applications, the control performance of a model predictive speed controller will deteriorate if the control system is disturbed, particularly in the presence of significant parameter mismatches and/or external disturbances. On the one hand, the control performance of the MPC speed controller depends on an explicit model of the controlled system which is used to forecast the behavior of the controlled plant and to compute the optimal value of the control action sequence with the cost function. If the mechanical parameters of the PMSM system, including the viscous friction coefficient and rotational inertia, are unknown or mismatched, the state-space model of the controlled system cannot be accurately established. Consequently, the optimal control action sequence cannot be obtained from the MPC controller, and the system cannot precisely control the speed. On the other hand, external disturbances, which are inevitably in PMSM control systems, significantly degrade the speed control stability if no appropriate compensation method is implemented. This is because the model predictive controller does not consider the disturbance terms in its cost function, making it difficult to directly react to and promptly reject the disturbances [12]. Although the MPC method can asymptotically mitigate the influence of slight parameter mismatches or external disturbances through feedback regulation, this will lead to undesirable results.

To overcome the impact of parameter mismatches and external disturbances on the model predictive controller, parameter estimation and disturbance compensation techniques are required. Some of the parameter identification techniques have been proposed, such as model reference adaptive system (MRAS) [21,22], the recursive least squares (RLS) method [23,24], extended Kalman filter (EKF) method [25], and observer-based method [26-29].

Among these advanced parameter estimation algorithms, observer-based methods, including disturbance observer (DOB) and sliding mode observer (SMO), have been widely used in practical applications, owing to their simple design and implementation for parameter estimation [26,27]. In addition, for PMSM systems, which inevitably face external disturbances, the observer can be used as a disturbance observer. After parameter estimation, the observer can estimate the external disturbances and immediately provide feedback to the speed controller. Compared with the DOB-based method, the SMO-based method has many advantages such as robustness to disturbances, insensitivity to parameter variations, and flexible gain coefficient adjustment [27,30]. In References [27,28], an extended sliding mode observer (ESMO) was applied to estimate the system parameters, obtaining good observation results. In References [31,32], an ESMO was employed to observe external disturbances, and a feed-forward compensation technique was used to compensate the disturbances. In Reference [29], the low-pass filter (LPF) effect and the chattering phenomenon of the SMO were analyzed. The SMO can be used to accurately observe the error of mismatched parameters with reduced chattering by 
properly designing the control and feedback gains. This observer compromises between the response speed and chattering suppression. In Reference [32], a soft-switching SMO with a flexible boundary layer was designed using a sinusoidal saturation function to reduce the chattering phenomenon, while maintaining the disturbance rejection property. In References [33,34], an integral terminal sliding mode control method was proposed to achieve faster convergence and to reduce the steady-state tracking errors. In References [31,35], a novel approach law with a variable gain was proposed to improve the dynamic response performance and reduce chattering.

Given the aforementioned problems, this paper proposes an optimal DMPC with an ESMO (DMPC+ESMO) to improve the speed control and disturbance rejection performances of a PMSM system. Firstly, when the model of the controlled system is inaccurate or unknown, an ESMO with an integral sliding surface is established, and the designed ESMO is regarded as an extended sliding mode parameter observer (ESMPO) to identify the mechanical parameters of the PMSM system. After accurately determining the mechanical parameters, a discrete state-space model is employed using the mechanical parameters of the PMSM system, and a DMPC is designed for the speed loop of the system. An optimal control action sequence is then obtained by minimizing the cost function. In addition, speed-tracking errors and speed fluctuations will exist when the PMSM is running due to external load disturbances. Thus, a feed-forward compensation technology including an ESMO was incorporated into the system. The designed ESMO is regarded as an ESMDO to observe the external disturbances and immediately provide feedback to the speed controller and to allow the speed controller to compensate for the observed disturbances. Finally, a DMPC along with an ESMO method was developed for the speed loop of the PMSM system.

The rest of this paper is organized as follows. In Section 2, the mathematical model of the PMSM system and the implementation approach of the DMPC are introduced. In Section 3, the design of the ESMO and the procedure of the parameter observation method are presented. In Section 4, a simulation using MATLAB and the results of an experiment conducted on a digital control system using the DMPC+ESMO method for a PMSM system are presented. The conclusions of this study are given in Section 5.

\section{Designof Model Predictive Controller}

\subsection{Mathematical Model of the PMSM}

For a surface-mounted PMSM, the current mathematical model in the $d q$-synchronous reference frame can be expressed as follows [18]:

$$
\left\{\begin{array}{l}
u_{d}=R_{s} i_{d}+L_{d} \frac{d i_{d}}{d t}-\omega_{m} n_{p} L_{q} i_{q} \\
u_{q}=R_{s} i_{q}+L_{q} \frac{d i_{q}}{d t}+\omega_{m} n_{p}\left(L_{d} i_{d}+\psi_{f}\right)
\end{array}\right.
$$

where $i_{d}$ and $i_{q}$ are the stator currents in the $d q$-axis, $u_{d}$ and $u_{q}$ are the stator voltages in the $d q$-axis, $L_{d}=L_{q}=L_{s}$ is the stator winding inductance, $R_{s}$ is the stator winding resistance, $\psi_{f}$ is the permanent magnet flux linkage, $\omega_{m}$ is the rotor mechanical angular velocity, and $n_{p}$ is the number of pole pairs.

For a rotor flux orientation control strategy $\left(i_{d}=0\right)$, the mechanical motion equation can be written in the $d q$-synchronous rotating reference frame, and the mathematical model of a PMSM system can be expressed as follows:

$$
\begin{gathered}
J \frac{d \omega_{m}}{d t}=T_{e}-B \omega_{m}-T_{L} \\
T_{e}=\frac{3}{2} n_{p} \psi_{f} i_{q}=K_{t} i_{q}
\end{gathered}
$$

where $J$ is the moment of inertia, $T_{e}$ is the electromagnetic torque, $T_{L}$ is the load torque, $B$ is the viscous damping coefficient, and $K_{t}$ is the torque coefficient. Figure 1 shows the structure of the optimized DMPC with an ESMO. 


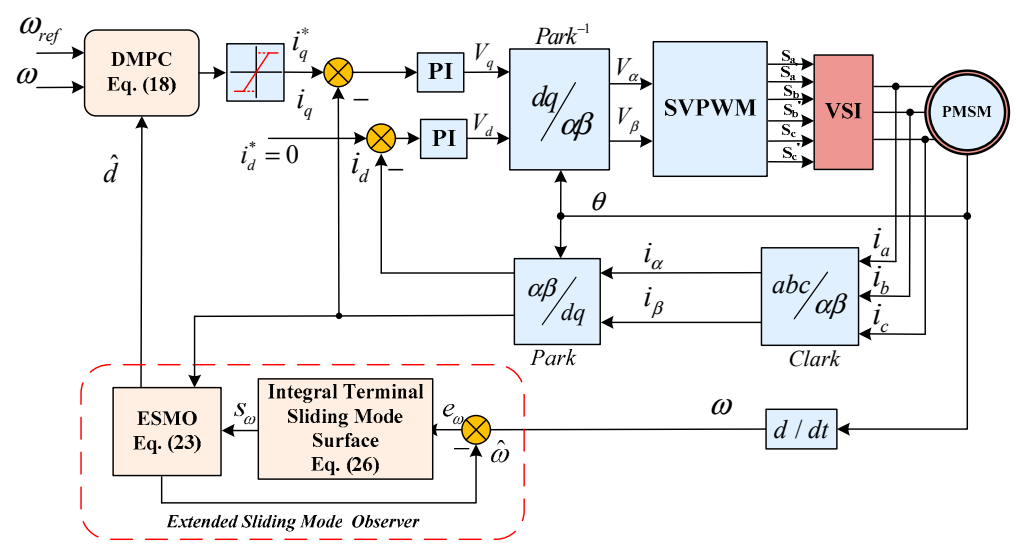

Figure 1. Structure diagram of the optimized discrete model predictive controller with an extended sliding mode observer.

\subsection{Design of DMPC for the PMSM}

In this paper, a DMPC is designed for the speed loop. To realize computer implementation, an embedded integrator is embedded in the MPC design. The integrator helps reduce the uncertainty of the system in applications and remove the load disturbance torque [14]. In the absence of external disturbances, Equation (2) can be rewritten as follows:

$$
\frac{d \omega_{m}}{d t}=\frac{K_{t}}{J} i_{q}-\frac{B}{J} \omega_{m}
$$

A forward Euler algorithm is applied to Equation (4), such that the discrete-time expression of the predicted rotor mechanical angular velocity at the next sampling instant can be written as follows:

$$
\omega_{m}(k+1)=\left(1-\frac{B T_{s}}{J}\right) \omega_{m}(k)+\frac{K_{t} T_{s}}{J} i_{q}(k)
$$

where $T_{s}$ is the sampling period.

Thereafter, a discrete state-space model of the PMSM system is used to predict the future outputs online over a defined predicted horizon. In this instance, the predicted output of the system can be expressed as follows:

$$
\left\{\begin{array}{l}
x_{m}(k+1)=A_{m} x_{m}(k)+B_{m} u(k) \\
y_{m}(k)=C_{m} x_{m}(k)
\end{array}\right.
$$

where, $A_{m}=\left(1-\frac{B T_{s}}{J}\right) \quad B_{m}=\frac{K_{t} T_{s}}{J} \quad C_{m}=1, x_{m}$ is the state vector of the state-space model, $A_{m}$, $B_{m}$, and $C_{m}$ are the coefficients of the state equation, and $y_{m}$ is the output of the prediction model. In this PMSM speed control system, the state variable $x_{m}$ is the rotor mechanical angular velocity $\omega_{m}$, and $y_{m}=x_{m}$.

Moreover, to realize incremental control in the embedded system, the above state-space equation, i.e., Equation (6), is rewritten as follows:

$$
\begin{aligned}
& \overbrace{\left[\begin{array}{l}
\Delta x_{m}(k+1) \\
y(k+1)
\end{array}\right]}^{x(k+1)}=\overbrace{\left[\begin{array}{ll}
A_{m} & 0 \\
C_{m} A_{m} & 1
\end{array}\right]\left[\begin{array}{l}
\Delta x_{m}(k) \\
y(k)
\end{array}\right]}^{A}+\overbrace{\left[\begin{array}{c}
B_{m} \\
C_{m} B_{m}
\end{array}\right]}^{x(k)} \Delta u(k) \\
& y(k)=\overbrace{\left[\begin{array}{ll}
0 & 1
\end{array}\right]\left[\begin{array}{c}
\Delta x_{m}(k) \\
y(k)
\end{array}\right]}^{B}
\end{aligned}
$$


where

$$
\begin{aligned}
& \left\{\begin{array}{l}
\Delta x_{m}(k+1)=x_{m}(k+1)-x_{m}(k) \\
\Delta x_{m}(k)=x_{m}(k)-x_{m}(k-1) \\
\Delta u(k)=u(k)-u(k-1)
\end{array}\right. \\
& x_{m}(k+1)-x_{m}(k) \\
& =A_{m}\left(x_{m}(k)-x_{m}(k-1)\right)+B_{m}(u(k)-u(k-1)) \\
& =A_{m} \Delta x_{m}(k)+B_{m} \Delta u(k) \\
& y(k+1)-y(k) \\
& =C_{m}\left(x_{m}(k+1)-x_{m}(k)\right)=C_{m} \Delta x_{m}(k+1) \text {. } \\
& =C_{m} A_{m} \Delta x_{m}(k)+C_{m} B_{m} \Delta u(k)
\end{aligned}
$$

The new state variables are defined by the differences between the states for any two successive sample instants, and the new state space model equations are obtained.

$$
\left\{\begin{array}{l}
x(k+1)=A x(k)+B \Delta u(k) \\
y(k)=C x(k)
\end{array}\right.
$$

where $x(k)=\left[\Delta x_{m}(k)^{T} y(k)\right]^{T}, \boldsymbol{A}=\left[\begin{array}{cc}A_{m} & 0 \\ C_{m} A_{m} & 1\end{array}\right] \quad \boldsymbol{B}=\left[\begin{array}{l}B_{m} \\ C_{m} B_{m}\end{array}\right] \quad \boldsymbol{C}=\left[\begin{array}{ll}0 & 1\end{array}\right]$.

It is assumed that at the current sampling instant $k(k>0)$, the state variable vector $x(k)$ is the current information of the controlled plant, made available through measurement. With the current information of the state variable $x(k)$, the future state variables can be predicted for $N_{p}$ sampling instants, where $N_{p}$ is the prediction horizon. According to the state-space model (8), the future state variables can be predicted sequentially using the future control action sequence $\Delta u$.

$$
\begin{aligned}
x(k+1 \mid k) & =\boldsymbol{A} x(k)+\boldsymbol{B} \Delta u(k) \\
x(k+2 \mid k) & =\boldsymbol{A} x(k+1 \mid k)+\boldsymbol{B} \Delta u(k+1) \\
& =\boldsymbol{A}^{2} x(k)+\boldsymbol{A} \boldsymbol{B} \Delta u(k)+\boldsymbol{B} \Delta u(k+1) \\
& \vdots \\
x\left(k+N_{P} \mid k\right) & =\boldsymbol{A}^{N_{p}} x(k)+\boldsymbol{A}^{N_{p}-1} \boldsymbol{B} \Delta u(k)+\boldsymbol{A}^{N_{p}-2} \boldsymbol{B} \Delta u(k+1) \\
& +\ldots+\boldsymbol{A}^{N_{p}-N_{c}} \boldsymbol{B} \Delta u\left(k+N_{c}-1\right)
\end{aligned}
$$

where $x(k+m \mid k)$ is the predicted state variable at the sampling instant $k+m$, which is calculated with the current state variable $x(k)$, and $N_{c}\left(N_{c} \leq N_{p}\right)$ is the control horizon.

According to the state-space model (8) and (9), with the state variable information $x(k)$ and the future control action $\Delta u$, the predicted output for the next $N_{p}$ instantscan be predicted.

$$
\begin{aligned}
y(k+1 \mid k) & =\boldsymbol{C A} x(k)+\boldsymbol{C B} \Delta u(k) \\
y(k+2 \mid k) & =\boldsymbol{C} \boldsymbol{A}^{2} x(k)+\boldsymbol{C A} \boldsymbol{B} \Delta u(k)+\boldsymbol{C} \boldsymbol{B} \Delta u(k+1) \\
& \vdots \\
y\left(k+N_{P} \mid k\right) & =\boldsymbol{C} \boldsymbol{A}^{N_{p}} x(k)+\boldsymbol{C} \boldsymbol{A}^{N_{p}-1} \boldsymbol{B} \Delta u(k)+C \boldsymbol{A}^{N_{p}-2} \boldsymbol{B} \Delta u(k+1) \\
& +\ldots+\boldsymbol{C} \boldsymbol{A}^{N_{p}-N_{c}} \boldsymbol{B} \Delta u\left(k+N_{c}-1\right)
\end{aligned}
$$

where $y(k+m \mid k)$ is the predicted output of the system at the sampling instant $k$.

The predicted output vectors for the next $N_{p}$ steps of the samples can then be obtained.

$$
Y=\boldsymbol{F} x(k)+G \Delta U
$$


where

$$
\begin{aligned}
& \left\{\begin{array}{l}
Y=\left[\begin{array}{llll}
y(k+1 \mid k) & y(k+2 \mid k) & \ldots & y\left(k+N_{p}\right)
\end{array}\right]^{T} \\
\Delta U=\left[\begin{array}{llll}
\Delta u(k) & \Delta u(k+1) & \ldots & \Delta u\left(k+N_{c}-1\right)
\end{array}\right]^{T}
\end{array}\right. \\
& \boldsymbol{F}=\left[\begin{array}{c}
C A \\
C A^{2} \\
C A^{3} \\
\vdots \\
C A^{N_{p}}
\end{array}\right] G=\left[\begin{array}{ccccc}
C B & 0 & 0 & \ldots & 0 \\
C A B & C B & 0 & \ldots & 0 \\
C A^{2} B & C A B & C B & \ldots & 0 \\
\vdots & & & \ddots & \\
C A^{N_{P}-1} B & C A^{N_{P}-2} B & C A^{N_{P}-3} B & \ldots & C A^{N_{P}-N_{c}} \boldsymbol{B}
\end{array}\right] .
\end{aligned}
$$

According to the augmented state-space model (8), $\boldsymbol{F}$ is a $N_{p} \times 2$ matrix, $G$ is a $N_{p} \times N_{c}$ matrix.

\subsection{Closed Loop Implementation of DMPC}

The purpose of the speed loop optimal control is to determine the optimal incremental control action sequence with a cost function and to ensure that the predicted output of the system is as close as possible to the reference value. With the closed-loop feedback structure, the predictive control action sequence can be corrected in real time. Thus, the DMPC can guarantee the system output to track the command.

The reference vector, which is composed of the reference values, can be expressed as follows:

$$
\begin{aligned}
Y_{r} & =\overbrace{\left[\begin{array}{lll}
1 & 1 & \ldots
\end{array}\right]^{T}}^{N_{p}} y_{r}(k) \\
& =R_{y} y_{r}(k)
\end{aligned}
$$

where $Y_{r}$ is the reference vector for the next $N_{p}$ samples, $y_{r}$ is the set value for the sampling instant $k$, $R_{y}$ is a $N_{p}$ dimensional unit column vector in this controller.

The cost function $J_{o p t}$ that reflects the control objective is then defined as follows:

$$
J_{o p t}=\left(Y_{r}-Y\right)^{T} \boldsymbol{Q}\left(Y_{r}-Y\right)+\Delta U^{T} \boldsymbol{R} \Delta U
$$

where $Q$ is a $N_{p} \times N_{p}$ positive diagonal weight matrix, and $R$ is a $N_{c} \times N_{c}$ positive diagonal weight matrix. The first item of the cost function is used to ensure minimum error between the output and the reference value, and the second item of the cost function ensures a lower value of $\Delta U$ to suppress the oscillation of the system.

Combining the above with Equation (11), Equation (13) can be written as follows:

$$
\begin{aligned}
& J_{o p t}=\left(Y_{r}-\boldsymbol{F} x(k)\right)^{T} \boldsymbol{Q}\left(Y_{r}-\boldsymbol{F} x(k)\right) \\
& -2 \Delta U^{T} \boldsymbol{G}^{T} \boldsymbol{Q}\left(Y_{r}-\boldsymbol{F} x(k)\right)+\Delta \boldsymbol{U}^{T}\left(\boldsymbol{G}^{T} \boldsymbol{Q} \boldsymbol{G}+\boldsymbol{R}\right) \Delta U
\end{aligned}
$$

Here, the necessary condition for finding the optimal control action sequence $\Delta U$ that minimizing $J_{o p t}$ is $\frac{\partial J_{o p t}}{\partial \Delta U}=0$. In the absence of constraints, the global optimal control sequence can be obtained by solving this equation as follows:

$$
\Delta U=\left(\boldsymbol{G}^{T} \boldsymbol{Q G}+\boldsymbol{R}\right)^{-1} \boldsymbol{G}^{T} \boldsymbol{Q}\left(Y_{r}-\boldsymbol{F} x(k)\right)
$$


The optimal control action sequence for the next $N_{c}$ sampling instants can be obtained by minimizing the cost function (13); however, only the first one is applied to the plant as follows:

$$
\begin{aligned}
& \Delta u(k)=\overbrace{\left.\begin{array}{llll}
1 & 0 & \ldots & 0
\end{array}\right]}^{N_{N_{c}}} \Delta U \\
& =\overbrace{\left[\begin{array}{ll}
1 & 0 \ldots 0
\end{array}\right]}\left(\boldsymbol{G}^{T} \boldsymbol{Q G}+\boldsymbol{R}\right)^{-1} \boldsymbol{G}^{T} \boldsymbol{Q}\left(R_{y} y_{r}(k)-\boldsymbol{F} x(k)\right) \\
& =K_{y} y_{r}(k)-K_{x y} x(k)
\end{aligned}
$$

where $K_{y}$ is the first element of: $\left(G^{T} Q G+R\right)^{-1} G^{T} Q R_{y}$ and $K_{x y}$ is the first element of: $\left(\boldsymbol{G}^{T} Q G+R\right)^{-1} G^{T} Q F$.

The closed-loop system equation can be obtained by substituting Equation (16) into Equation (8).

$$
\begin{aligned}
x(k+1) & =\boldsymbol{A} x(k)-\boldsymbol{B} K_{x y} x(k)+\boldsymbol{B} K_{y} y_{r}(k) \\
& =\left(\boldsymbol{A}-\boldsymbol{B} K_{x y}\right) x(k)+\boldsymbol{B} K_{y} y_{r}(k)
\end{aligned}
$$

Because of the special structures of the augmented state-space model parameter matrices $A$ and $C$, the last column of the matrix $\boldsymbol{F}$ is identical to the unit column vector $R_{y}=[1,1 \ldots 1]^{\mathrm{T}}$. Therefore, $K_{y}$ is identical to the last element of $K_{x y}$, and $K_{x y}$ can be written as $K_{x y}=\left[K_{x} K_{y}\right]$. To further reflect the closed-loop structure and facilitate computer implementation, control action (16) can be rewritten as follows:

$$
\begin{aligned}
\Delta u(k) & =K_{y} y_{r}(k)-K_{x y} x(k) \\
& =K_{y} y_{r}(k)-\left[K_{x} K_{y}\right][\Delta x(k) y(k)]^{T} \\
& =K_{y}\left(y_{r}(k)-y(k)\right)-K_{x} \Delta x(k)
\end{aligned}
$$

The matrices $K_{x}$ and $K_{y}$ can be computed off-line, and the control action $u(k)$ can be computed on-line using Equation (18). Figure 2 shows the block diagram of the discrete-time MPC system.

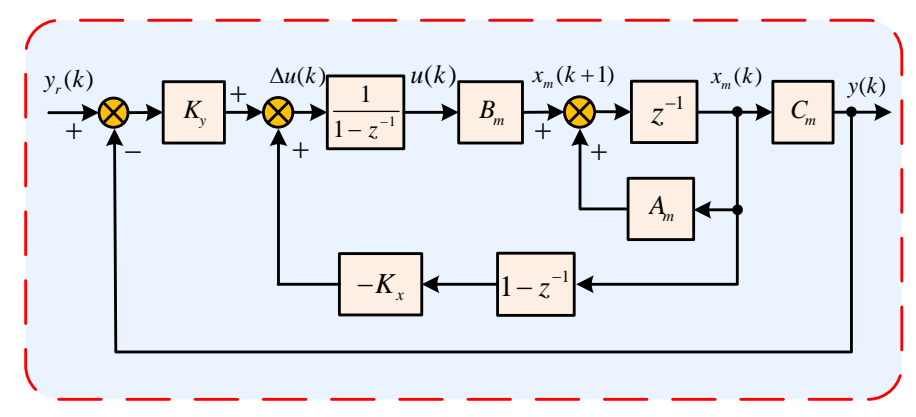

Figure 2. Block diagram of the discrete-time model predictive control system.

\section{Design of Extended Sliding Mode Observer}

\subsection{DesignofExtended Sliding Mode Observer}

Given that the PMSM system will be affected by parameter mismatches and external disturbances during operation, the mathematical model of a PMSM system for practical applications can be expressed as follows:

$$
\left(J_{0}+\Delta J\right) \frac{d \omega_{m}}{d t}=T_{e}-\left(B_{0}+\Delta B\right) \omega_{m}-T_{L}
$$

where $J=J_{0}+\Delta J$, and $B=B_{0}+\Delta B$. The parameters $B_{0}$ and $J_{0}$ are the initial values of the viscous damping coefficient and moment of inertia respectively. They can be determined based on experience and prior knowledge. $\Delta J$ and $\Delta B$ are parameter mismatch errors. 
Combining Equation (2) with Equation (19), the initial motion equation can be obtained:

$$
\left\{\begin{array}{l}
J_{0} \frac{d \omega_{m}}{d t}=T_{e}-B_{0} \omega_{m}-d \\
d=\Delta J \dot{\omega}+\Delta B \omega+T_{L}
\end{array}\right.
$$

where $d$ represents the system disturbances including parameter mismatch errors and external load disturbances.

In a PMSM drive system, the electrical time constant is significantly smaller than the mechanical time constant, and the sampling period is very short. The system disturbances change slowly compared to other system status signals in every sampling period of the speed loop. Thus, its first derivative is zero.

$$
\dot{d}(t)=0
$$

According to Equation (20), the mechanical angular velocity and the system disturbances $d$ are defined as state variables. The extended state space equation can be expressed as follows:

$$
\left\{\begin{array}{l}
{\left[\begin{array}{c}
\dot{\omega}_{m} \\
\dot{d}
\end{array}\right]=\left[\begin{array}{cc}
-B_{0} / J_{0} & -1 / J_{0} \\
0 & 0
\end{array}\right]\left[\begin{array}{c}
\omega_{m} \\
d
\end{array}\right]+\left[\begin{array}{c}
1 / J_{0} \\
0
\end{array}\right] T_{e}} \\
\omega_{m}=\left[\begin{array}{ll}
1 & 0
\end{array}\right]\left[\begin{array}{c}
\omega_{m} \\
d
\end{array}\right]
\end{array}\right.
$$

In the extended state space Equation (22), the mechanical angular velocity $\omega_{m}$ and the disturbance $d$ are regarded as observation targets. Thus, the ESMO can be constructed as follows:

$$
\begin{gathered}
{\left[\begin{array}{c}
\dot{\hat{\omega}}_{m} \\
\dot{\hat{d}}
\end{array}\right]=\left[\begin{array}{cc}
\frac{-B_{0}}{J_{0}} & \frac{-1}{J_{0}} \\
0 & 0
\end{array}\right]\left[\begin{array}{c}
\hat{\omega}_{m} \\
\hat{d}
\end{array}\right]+\left[\begin{array}{c}
\frac{1}{J_{0}} \\
0
\end{array}\right] T_{e}+\left[\begin{array}{l}
g_{s m o 1}\left(e_{\omega}\right) \\
g_{s m o 2}\left(e_{\omega}\right)
\end{array}\right]} \\
\hat{d}=\Delta \hat{J} \dot{\omega}+\Delta \hat{B} \omega+\hat{T}_{L}
\end{gathered}
$$

where $\hat{\omega}_{m}$ is the estimated value of the mechanical angular velocity, $\hat{d}$ is the estimated value of the system disturbances, $g_{\text {smo }}\left(e_{\omega}\right)$ is the sliding mode control function with the mechanical angular velocity observation error $e_{\omega}$. The observation error of the mechanicalangular velocity $e_{\omega}$ and the observation error ofthe system disturbances $e_{d}$ are defined as follows:

$$
\left\{\begin{array}{l}
e_{\omega}=\omega_{m}-\hat{\omega}_{m} \\
e_{d}=d-\hat{d}
\end{array}\right.
$$

The design of the sliding mode surface determines the observation quality of the SMO. The integral sliding mode surface can reduce the chattering of the system and the steady-state error and avoid the analysis of the second derivative. The integral terminal sliding surface is set as follows:

$$
s_{\omega}=e_{\omega}+c_{\omega} \int_{0}^{t} \operatorname{sgn}\left(e_{\omega}\right) d \tau
$$

where $c_{\omega}>0$ is a positive integral coefficient.

In applications, because of the difference calculation in the next part, it is necessary to further suppress the chattering problem. Therefore, a smooth switching function $\vartheta(x)$ is used instead of the traditional switching function $\operatorname{sgn}(x)$.

$$
\operatorname{sgn}(x)=\vartheta(x)=\frac{x}{|x|+\delta}
$$

where $\delta>0$ is a constant. 
Combining the above with Equations (22), (23), and (25), the equation for the observation error can be written as:

$$
\left\{\begin{array}{l}
\dot{e}_{\omega}=-\frac{B_{0}}{J_{0}} e_{\omega}-\frac{1}{J_{0}} e_{d}-g_{s m o 1}\left(e_{\omega}\right) \\
\dot{e}_{d}=-g_{s m o 2}\left(e_{\omega}\right)
\end{array}\right.
$$

By combining the above equation with Equation (23), the control law of the sliding mode disturbance observer is set as follows.

$$
\left\{\begin{array}{l}
g_{s m o 1}\left(e_{\omega}\right)=c_{\omega} \operatorname{sgn}\left(e_{\omega}\right)-\frac{B_{0}}{J_{0}} e_{\omega}+k_{1} \operatorname{sgn}\left(s_{\omega}\right) \\
g_{s m o 2}\left(e_{\omega}\right)=k_{2} \operatorname{sgn}\left(s_{\omega}\right)
\end{array}\right.
$$

Proof. The Lyapunov function candidate is considered.

$$
V=\frac{1}{2} s_{\omega}^{2}
$$

Differentiating $V$ with respect to time $t$ yields the following.

$$
\begin{aligned}
\dot{V} & =s_{\omega} \dot{s}_{\omega} \\
& =s_{\omega}\left(c_{\omega} \operatorname{sgn}\left(e_{\omega}\right)+\dot{e}_{\omega}\right) \\
& =s_{\omega}\left(c_{\omega} \operatorname{sgn}\left(e_{\omega}\right)-\frac{B_{0}}{J_{0}} e_{\omega}-\frac{1}{J_{0}} e_{d}-g_{s m o 1}\left(e_{\omega}\right)\right) \\
& =s_{\omega}\left(-\frac{1}{J_{0}} e_{d}-k_{1} \operatorname{sgn}\left(s_{\omega}\right)\right)
\end{aligned}
$$

where $B_{0}>0$, and $J_{0}>0$. To satisfy the finite-time Lyapunov stability theory, the derivative of the Lyapunov function $\dot{V} \leq 0$ should be determined. This requires that $s_{\omega}\left[-e_{d} / J_{0}-k_{1} \operatorname{sgn}\left(s_{\omega}\right)\right] \leq 0$, which can be simplified as follows:

$$
\left\{\begin{array}{c}
-\frac{e_{d}}{J_{0}}+k_{1}>0 \quad s_{\omega}<0 \\
-\frac{e_{d}}{J_{0}}-k_{1}<0 \quad s_{\omega} \geq 0
\end{array}\right.
$$

Therefore, the sliding mode control gain $k_{1}$ can be obtained as follows:

$$
k_{1}>\frac{1}{J_{0}}\left|e_{d}\right|
$$

This can ensure that the designed observer is stable and that any tracking error trajectory will converge to zero in a finite time.

On the other hand, based on the above ESMO, when the observer trajectory arrives at the sliding surface and remains there, the following condition should be satisfied.

$$
\left\{\begin{array}{l}
s_{\omega}=\dot{s}_{\omega}=0 \\
e_{\omega}=\dot{e}_{\omega}=0
\end{array}\right.
$$

According to Equations (26), (28), and (29), the following equation can be obtained.

$$
\left\{\begin{array}{l}
\dot{e}_{\omega}=-\frac{B_{0}}{J_{0}} e_{\omega}-\frac{1}{J_{0}} e_{d}-\left(c_{\omega} \operatorname{sgn}\left(e_{\omega}\right)-\frac{B_{0}}{J_{0}} e_{\omega}\right)-k_{1} \operatorname{sgn}\left(s_{\omega}\right) \\
\dot{e}_{d}=-k_{2} \operatorname{sgn}\left(s_{\omega}\right)
\end{array}\right.
$$

The following is obtained by substituting Equation (35) into (34).

$$
\left\{\begin{array}{l}
0=-\frac{1}{J_{0}} e_{d}-k_{1} \operatorname{sgn}\left(s_{\omega}\right) \\
\dot{e}_{d}=-k_{2} \operatorname{sgn}\left(s_{\omega}\right)
\end{array}\right.
$$


Equation (36) can be further simplified as follows.

$$
\left\{\begin{array}{l}
\dot{e}_{d}=\frac{k_{2}}{k_{1} J_{0}} e_{d} \\
e_{d}=C_{0} e^{\frac{k_{2}}{k_{1} J_{0}} t}
\end{array}\right.
$$

where $C_{0}$ is a constant, and $J_{0}>0$. To ensure that the observation error converges to zero, the observer feedback gain must be such that $k_{2}<0$. According to the above analysis, the system parameters will affect the gain of the observer. By properly adjusting the gain coefficient $k_{1}$ and $k_{2}$, the observer can achieve a good observation performance. Figure 3 shows a block diagram of the ESMO.

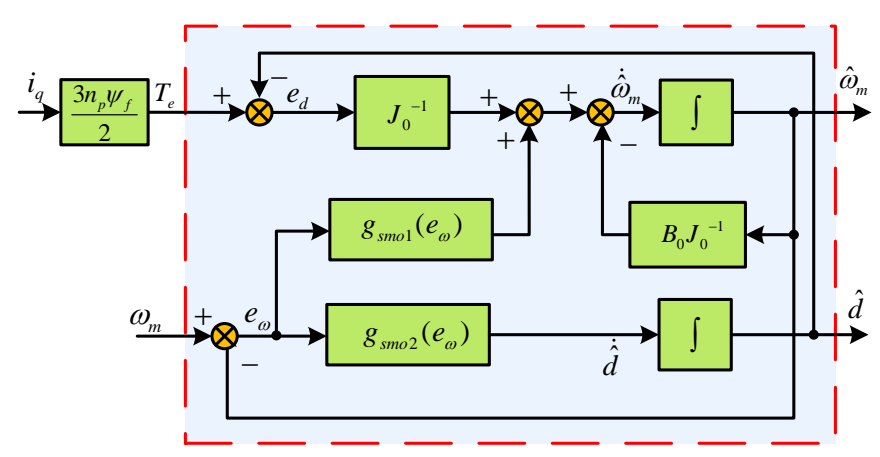

Figure 3. Block diagram of the extended sliding mode observer.

\subsection{Parameter Observation Steps}

According to Equation (24), the mechanical parameters can be extracted and calculated from the observation disturbances. The mechanical parameters are estimated in three steps [27]. Figure 4 shows the procedure diagram of mechanical parameter estimation. Firstly, the parameter $B$ should be estimated. In the first stage, the PMSM needs to be operated at two different steady-state speeds, and the parameter $B$ can be estimated from the measured velocity information and the observed disturbances. Secondly, the parameter $J$ can be estimated after the parameter $B$ is obtained and updated. In this stage, the PMSM needs to be operated under two different constant accelerations or decelerations, and the parameter $J$ can be estimated from the acceleration or deceleration information and the observed disturbances. Finally, after obtaining and updating the parameters $B$ and $J$, the ESMO can be regarded as an ESMDO, and the external load torque $T_{L}$ can be directly estimated from the observation $\hat{d}$.

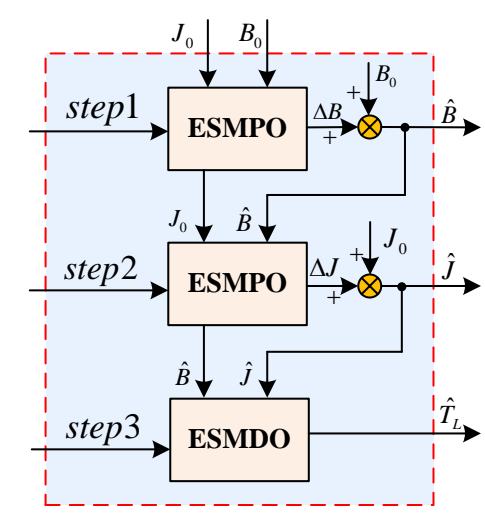

Figure 4. Procedure diagram of mechanical parameter estimation. 
An optimal DMPC cannot be established without determining the exact parameters. Therefore, a non-optimal PI speed controller based on a trial-and-error method was used to estimate the mechanical parameters. Although the non-optimal PI controller cannot achieve optimal control performance, only the steady-state information is needed in the parameter estimation process; the non-optimal PI controller has little impact on the parameter estimation process [29]. Figure 5 shows the principle diagram of parameter estimation.
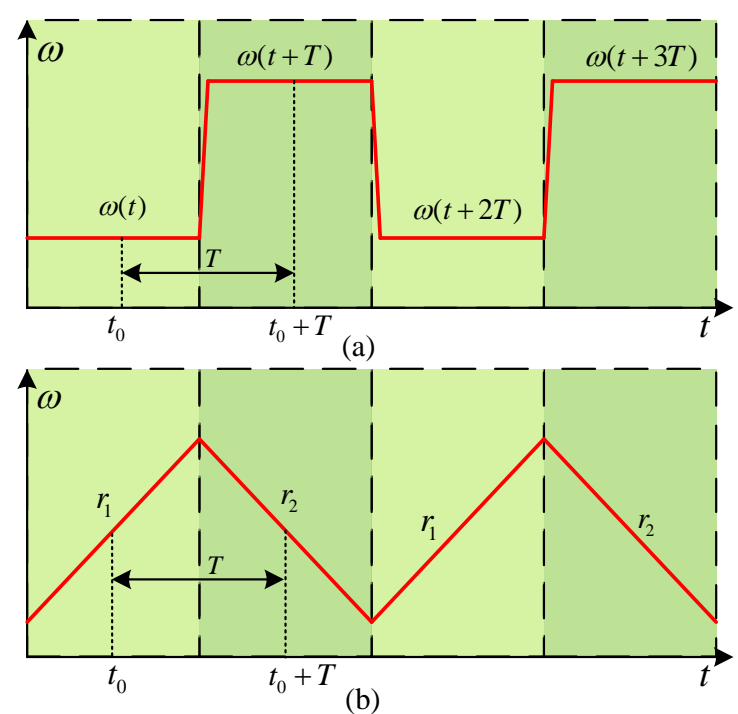

Figure 5. Principle diagram of parameter estimation: (a) Estimating $B$; (b) estimating $J$.

When estimating $B$, as shown in Figure 5 a, the PMSM needs to be operated at two different steady-state speeds, which satisfy the condition $\omega(t) \neq \omega(t+T)$ with their accelerations being zero. In Figure 5, $T$ is a predetermined time delay that keeps the system stable for a period of time under the two different speed commands. When the PMSM is operated at the first steady-state speed $\omega(t)$ for a period of $T$, according to Equation (24), the observed disturbance can be obtained as follows:

$$
\hat{d}(t)=\Delta \hat{\jmath} \dot{\omega}(t)+\Delta \hat{B} \omega(t)+T_{L 0}
$$

The observed disturbance for the second steady-state speed $\omega(t+T)$ can be obtained by changing the speed command and keeping it for a period of $T$ as follows:

$$
\hat{d}(t+T)=\Delta \hat{J} \dot{\omega}(t+T)+\Delta \hat{B} \omega(t+T)+T_{L 0}
$$

The load torque $T_{L 0}$ of the PMSM system is constant when the PMSM control system is in the steady state. It can be obtained by subtracting Equation (38) from (39).

$$
\hat{d}(t+T)-\hat{d}(t)=\Delta \hat{B} \omega(t+T)-\Delta \hat{B} \omega(t)
$$

Thus, the parameter mismatch error $\Delta \hat{B}$ can be obtained as follows:

$$
\Delta \hat{B}=\frac{\hat{d}(t+T)-\hat{d}(t)}{\omega(t+T)-\omega(t)}
$$


The observed value of the parameter $\Delta \hat{B}$ can be estimated as follows:

$$
\hat{B}=B_{0}+\Delta \hat{B}=B_{0}+\frac{\hat{d}(t+T)-\hat{d}(t)}{\omega(t+T)-\omega(t)}
$$

After the parameter $B$ is estimated accurately, the initial value $B_{0}$ in Equation (23) can be updated using $\hat{B}$, and it should satisfy $\Delta B=B-\hat{B}=0$.

As shown in Figure $5 b$, when estimating $J$, the PMSM needs to be operated at a constant acceleration state $r_{1}$ for a period of $T$. According to Equation (24) and given that $\Delta B=0$, the observed disturbance can be obtained as follows:

$$
\hat{d}(t)=\Delta \hat{\jmath} \dot{\omega}(t)+T_{L 0}=\Delta \hat{J} \cdot r_{1}+T_{L 0}
$$

The observed disturbance for the other constant acceleration state $r_{2}$ can be obtained by changing the acceleration command and keeping it for a period of $T$.

$$
\hat{d}(t+T)=\Delta \hat{\jmath} \dot{\omega}(t+T)+T_{L 0}=\Delta \hat{J} \cdot r_{2}+T_{L 0}
$$

Subtracting Equation (44) from Equation (43) gives the following:

$$
\hat{d}(t+T)-\hat{d}(t)=\Delta \hat{J} \cdot r_{2}-\Delta \hat{J} \cdot r_{1}
$$

Thus, the parameter mismatch error $\Delta \hat{J}$ can be obtained as follows:

$$
\Delta \hat{J}=\frac{\hat{d}(t+T)-\hat{d}(t)}{r_{2}-r_{1}}
$$

Therefore, the parameter $\hat{J}$ can be estimated as follows:

$$
\hat{J}=J_{0}+\Delta \hat{J}=J_{0}+\frac{\hat{d}(t+T)-\hat{d}(t)}{r_{2}-r_{1}}
$$

When the parameters $B$ and $J$ are estimated accurately, the initial $B_{0}$ and $J_{0}$ in Equation (24) can be replaced by the estimated parameters $\hat{B}$ and $\hat{\jmath}$. Now, $\Delta J=J-\hat{J}=0$, and $\Delta B=B-\hat{B}=0$. Thus, the disturbance term $\hat{d}$ can be expressed as follows.

$$
\hat{d}(t)=T_{L}
$$

The above analysis shows that the proposed ESMO can observe the system disturbances in real-time. In practical applications, the proposed ESMO can be used to optimize the speed controller by estimating the system parameters $B$ and $J$. Moreover, it can be used to improve the anti-disturbance ability of the system by estimating the external load torque $T_{L}$ and compensating it online.

\section{Simulation and Experimental Results}

To demonstrate the effectiveness of the proposed control method, a model of the PMSM system was established using MATLAB/Simulink. Experiments were then conducted on a PMSM drive system. This section reports the results. Table 1 lists the actual system parameters of the PMSM. 
Table 1. Parameters of the PMSM.

\begin{tabular}{cc}
\hline Parameter & Value \\
\hline Armature resistance $\left(R_{S}\right)$ & $4.3(\Omega)$ \\
Armature inductance $\left(L_{s}\right)$ & $20.1(\mathrm{mH})$ \\
Torque coefficient $\left(K_{t}\right)$ & $0.498(\mathrm{~N} \cdot \mathrm{m} / \mathrm{A})$ \\
Permanent magnet flux linkage $\left(\psi_{f}\right)$ & $0.083(\mathrm{~Wb})$ \\
Number of pole pairs $\left(n_{p}\right)$ & 4 \\
Viscous friction coefficient $(B)$ & $1.08 \times 10^{-3}(\mathrm{~N} \cdot \mathrm{m} \cdot \mathrm{s} / \mathrm{rad})$ \\
Rotational inertia $(J)$ & $4.7 \times 10^{-4}\left(\mathrm{Kg} \cdot \mathrm{m}^{2}\right)$ \\
\hline
\end{tabular}

\subsection{Simulation Resultsand Analysis}

The simulation was conducted under parameter mismatches and a step external load disturbance to test the performance of the proposed ESMO. At the stage of estimating $B$ and $J$, different initial values $B_{0}$ and $J_{0}$ are set to the model. Figures 6 and 7 show the observed results of the parameter $B$. Figures 8 and 9 show the observed results of the parameter $J$. When estimating $T_{L}$, the system applies an external disturbance of $1 \mathrm{~N} \cdot \mathrm{m}$ at $1 \mathrm{~s}$ and then unloads it at $2 \mathrm{~s}$. Figure 10 shows the observed results of the external load disturbance $T_{L}$.

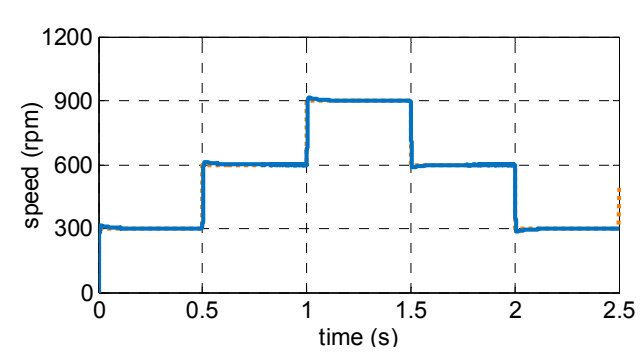

(a)

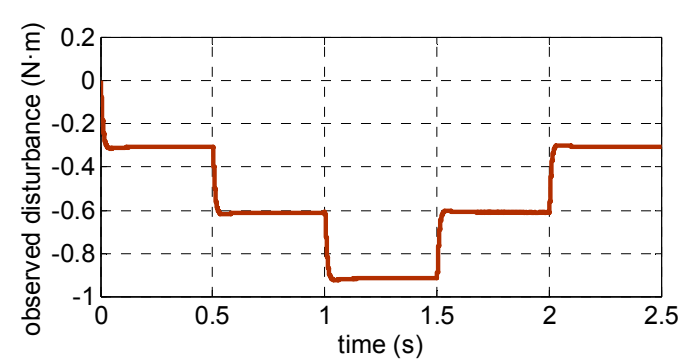

(b)

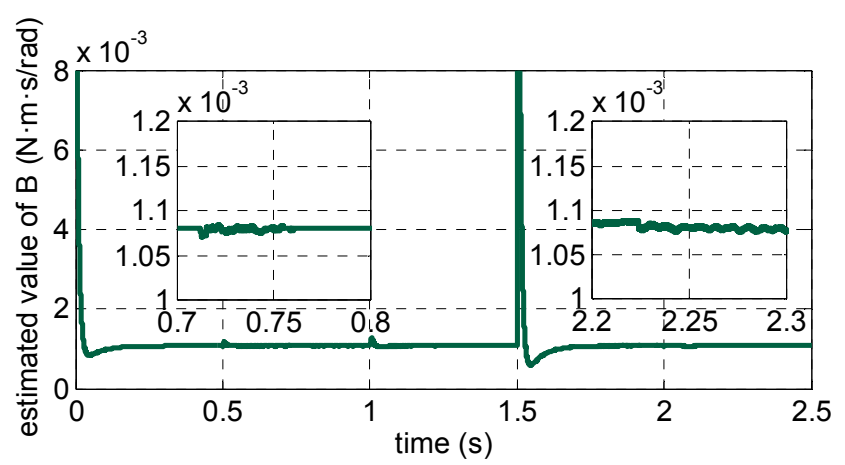

(c)

Figure 6. Simulation results under a speed step of $\pm 300 \mathrm{rpm}$ for $B_{0}=10 B$ : (a) Measured speed, (b) observed disturbance value for parameter mismatch error $\Delta B$, (c) estimated value of parameter $B$. 


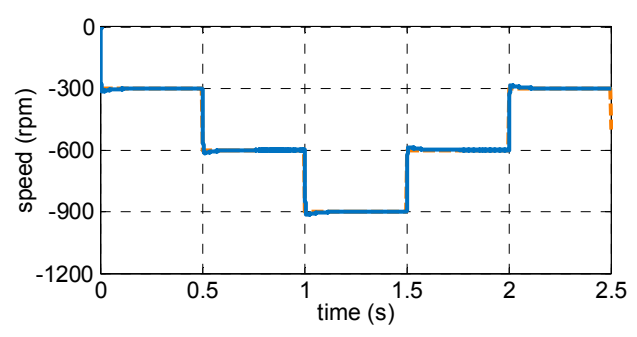

(a)

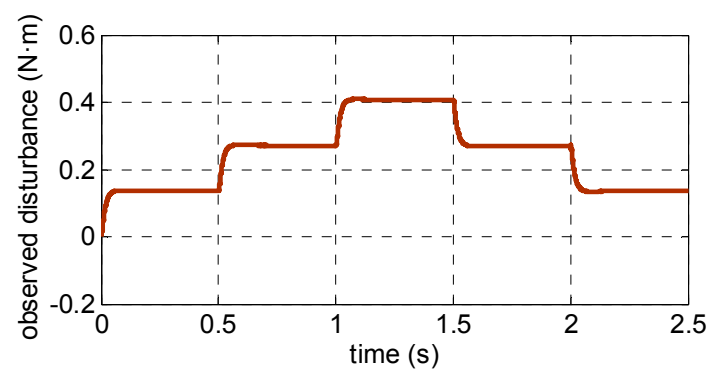

(b)

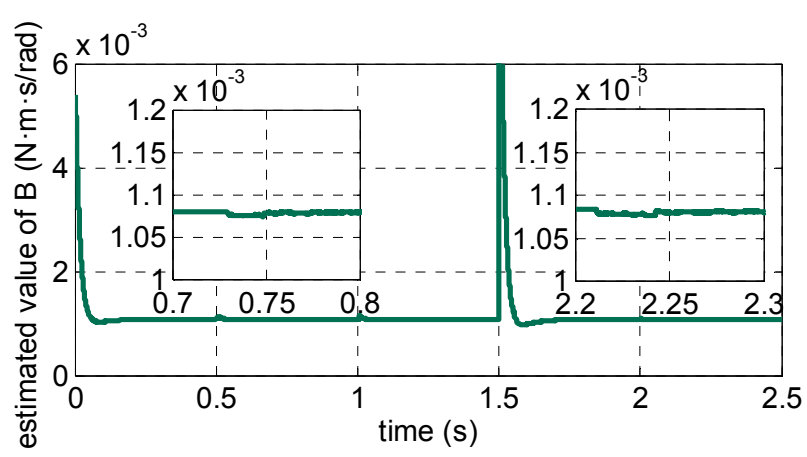

(c)

Figure 7. Simulation results under a speed step of $\pm 300 \mathrm{rpm}$ for $B_{0}=5 B$ : (a) Measured speed; (b) observed disturbance value for parameter mismatch error $\Delta B$; (c) estimated value of parameter $B$.

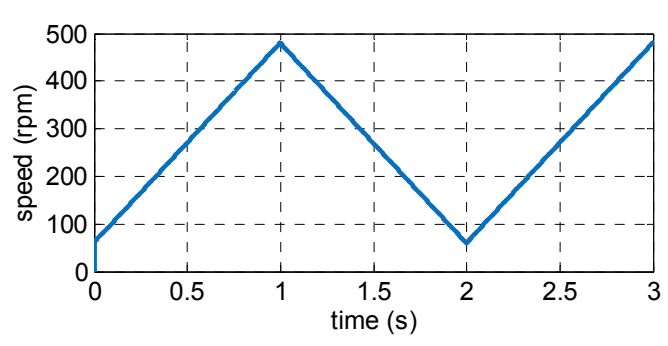

(a)

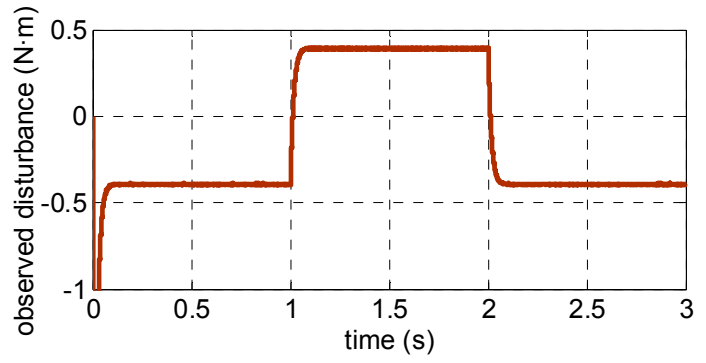

(b)

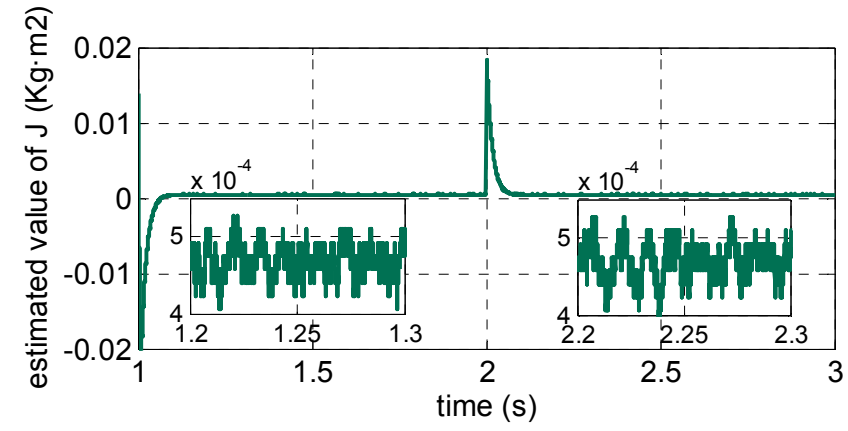

(c)

Figure 8. Simulation results under an acceleration of $\pm 420 \mathrm{rpm} / \mathrm{s}$ for $J_{0}=20 \mathrm{~J}$ : (a) Measured speed; (b) observed disturbance value for parameter mismatch error $\Delta J$; (c) estimated value of parameter $J$. 


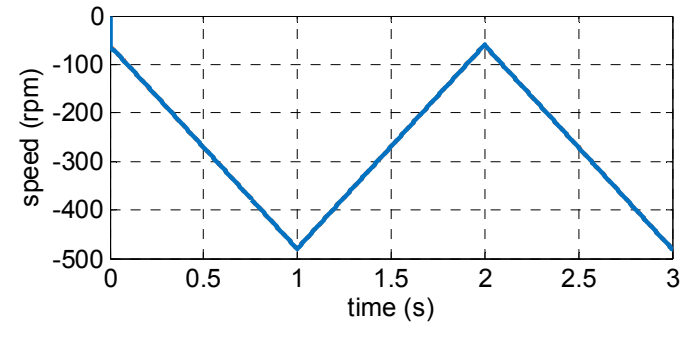

(a)

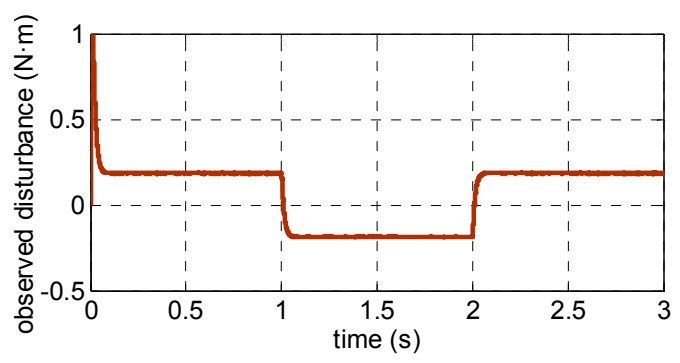

(b)

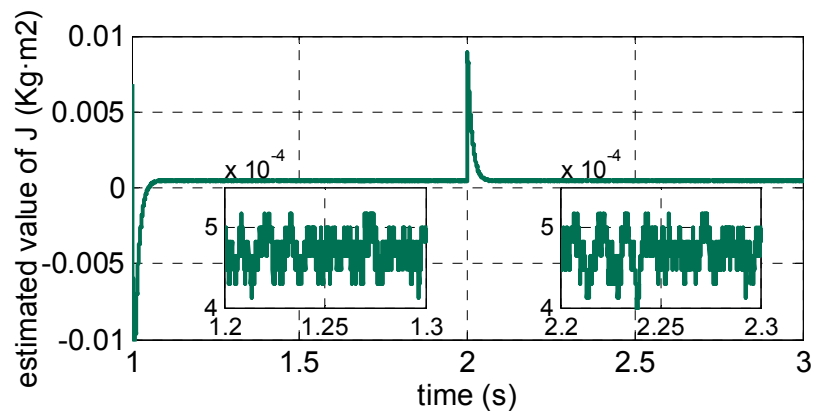

(c)

Figure 9. Simulation results under an acceleration of $\pm 420 \mathrm{rpm} / \mathrm{s}$ for $J_{0}=10 \mathrm{~J}$ : (a) Measured speed; (b) observed disturbance value for parameter mismatch error $\Delta J$; (c) estimated value of parameter $J$.

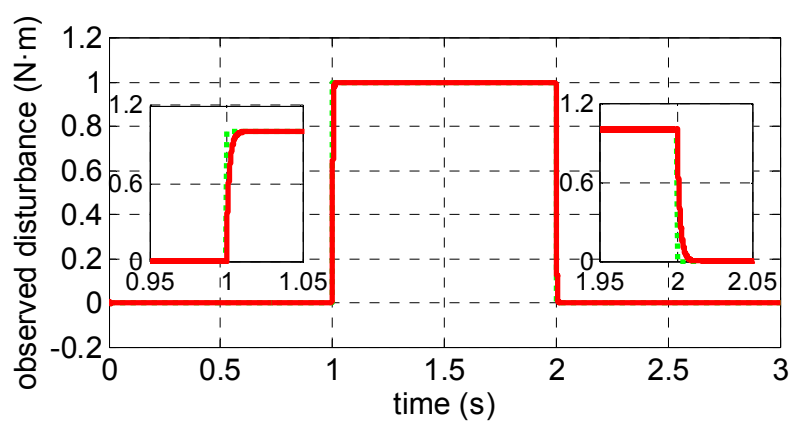

Figure 10. Simulation curves of observations based on the extended sliding mode observer (ESMO) for a step disturbance of $1 \mathrm{~N} \cdot \mathrm{m}$.

As shown in Figures 6 and 7, for different initial values of $B_{0}$, the estimated value $\hat{B}$ can be made to converge to the real value by operating the motor at different stable speeds. As shown in Figures 8 and 9 , for different initial values of $J_{0}$, the estimated value $J$ can be made to converge to the real value by operating the motor at track different accelerations. After accurately obtaining the mechanical parameters, the proposed observer can be used to observe the external load disturbances. As shown in Figure 10, the proposed ESMO can estimate the external load disturbance precisely and quickly.

The above simulation results show that in the case of parameter mismatches, the proposed observer can estimate and update the observed parameters in real time. Moreover, after updating the parameters, the ESMO can estimate the external disturbance promptly and accurately and provide the observed disturbances as feed-forward compensation for the speed controller.

\subsection{Experimental Results and Analysis}

To further verify the performance of the proposed DMPC with the ESMO method, experiments based on a PMSM drive system are conducted. Figure 11 shows the experimental platform. The proposed control method is realized based on the DSP-TMS320F28335and FPGA-EP3C40F324-based 
drive setups. The sampling frequency of the speed loop is $1 \mathrm{kHz}$, and the counterpart frequency of the current loop is $10 \mathrm{kHz}$.

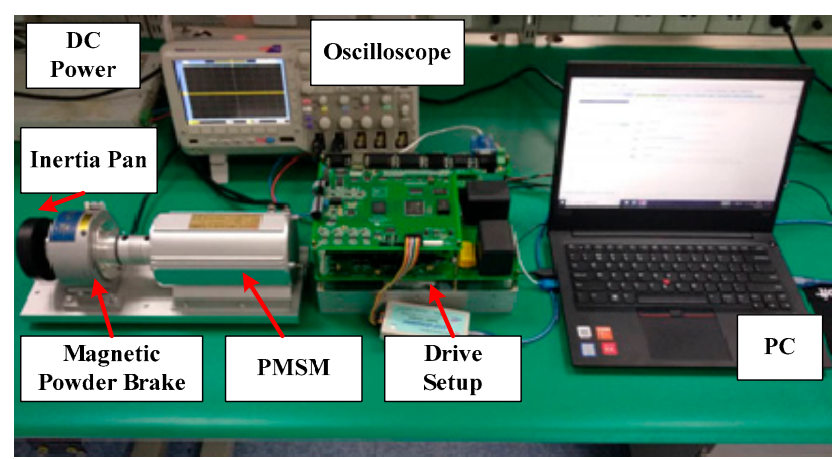

Figure 11. Image of the experimental platform.

According to the method described above, the experiment is conducted in three steps. Firstly, the parameter $B$ should be observed and updated. As shown in Figure 12a, the initial value $B_{0}$ is set to ten times the true value, i.e., $B_{0}=10 B$, and the PMSM is operated at alternate speeds of 300 and $600 \mathrm{rpm}$. Figure $12 \mathrm{~b}$ shows the observed results for the parameter mismatch error $\Delta B$. Figure $12 \mathrm{c}$ shows the estimated result of the parameter $\hat{B}$. As shown in Figure $13 \mathrm{a}$, the initial value $B_{0}$ is set to five times the true value, i.e., $B_{0}=5 B$, and the PMSM is operated at alternate speeds of -300 and $-600 \mathrm{rpm}$. Figure $13 \mathrm{~b}$ shows the observed results for the parameter mismatch error $\Delta B$. Figure $13 \mathrm{c}$ shows the estimated results of the parameter $\hat{B}$.

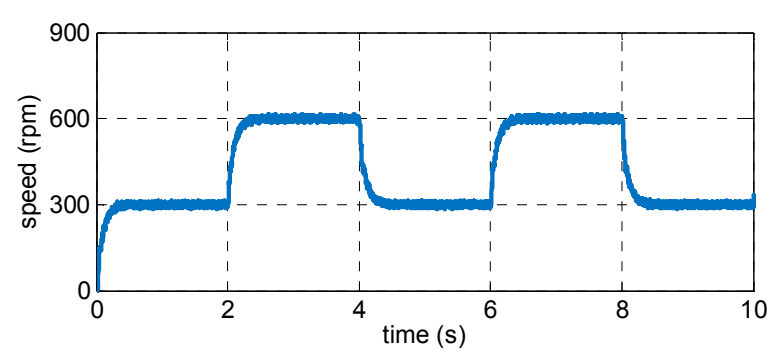

(a)

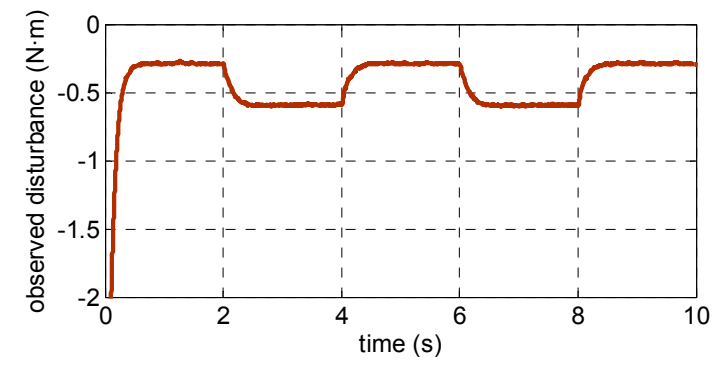

(b)

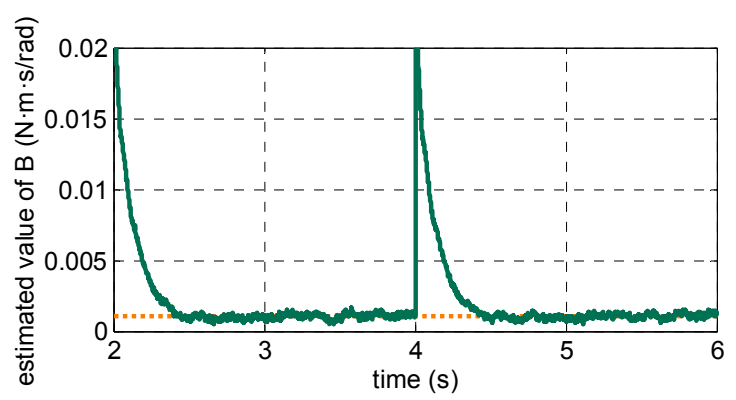

(c)

Figure 12. Experimental results under alternate speeds of 300 and $600 \mathrm{rpm}$ for $B_{0}=10 B$ : (a) Measured speed; (b) observed disturbance value for parameter mismatch error $\Delta B$; (c) estimated value of parameter $B$. 


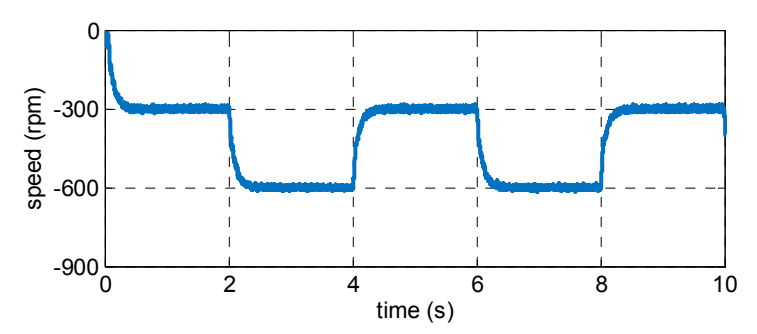

(a)

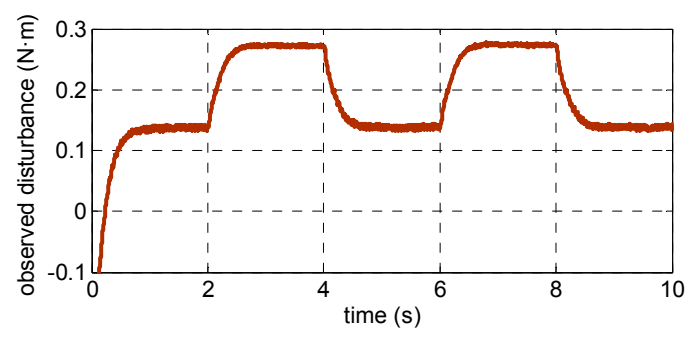

(b)

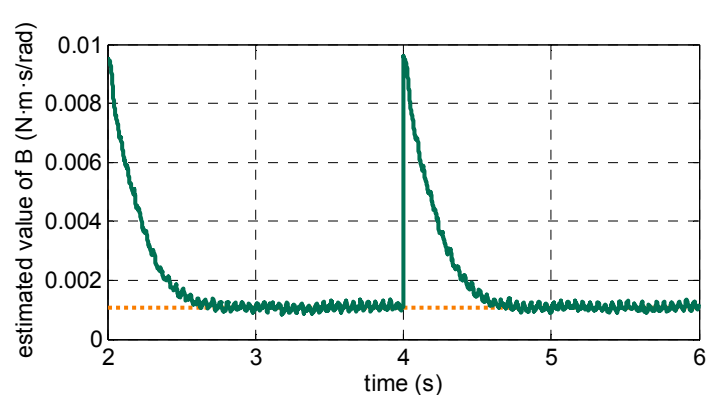

(c)

Figure 13. Experimental results under alternate speeds of -300 and $-600 \mathrm{rpm}$ for $B_{0}=5 B$ : (a) Measured speed; (b) observed disturbance value for parameter mismatch error $\Delta B$; (c) estimated value of parameter $B$.

The parameter $J$ is then observed and updated. As shown in Figure $14 \mathrm{a}$, the initial value $J_{0}$ is set to 20 times the true value $J$, i.e., $J_{0}=20 \mathrm{~J}$, and the motor is operated to track the acceleration of $\pm 420 \mathrm{rpm} / \mathrm{s}$ in the forward direction. Figure $14 \mathrm{~b}$ shows the observed results for the parameter mismatch error $\Delta J$. Figure $14 \mathrm{c}$ shows the estimated results of the parameter $\hat{J}$. As shown in Figure $15 \mathrm{a}$, the initial value $J_{0}$ is set to ten times the true value $J$, i.e., $J_{0}=10 \mathrm{~J}$, and the motor is operated to track the acceleration instruction of $\pm 420 \mathrm{rpm} / \mathrm{s}$ in the negative direction. Figure $15 \mathrm{~b}$ shows the observed results for the parameter mismatch error $\Delta J$. Figure $15 \mathrm{c}$ shows the estimated results of the parameter $\hat{J}$.

Finally, the observed results of the mechanical parameters can be used to optimize the speed controller and update the observer. When the motor is operated at a given speed of $600 \mathrm{rpm}$, Figure 16 shows the results under the PI and DMPC method. Then, the system applies an external load disturbance of $1 \mathrm{~N}$ at $3 \mathrm{~s}$ and then unloads it at $6 \mathrm{~s}$. Figure 17 shows the results obtained using the PI speed controller. Figure 18 shows the results obtained using the DMPC+ESMO method.

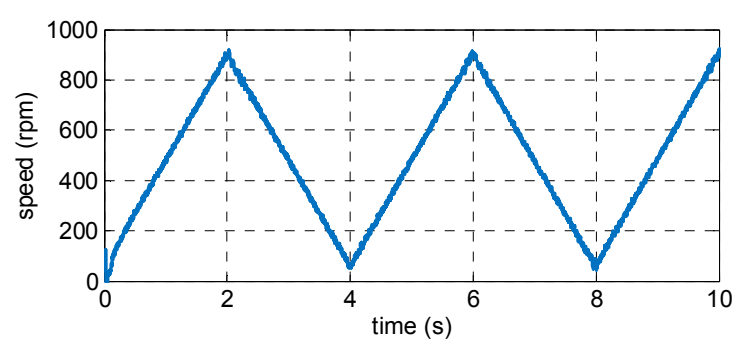

(a)

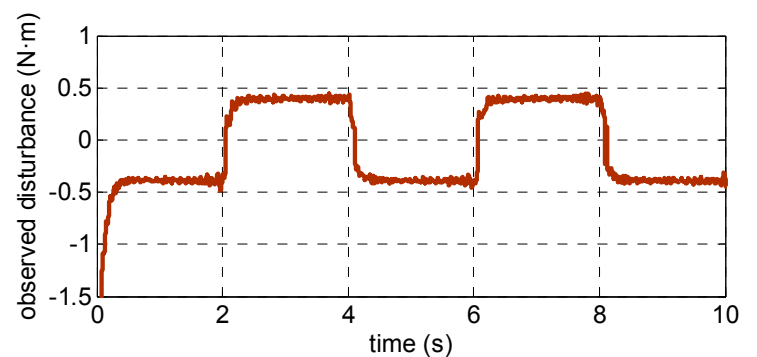

(b)

Figure 14. Cont. 


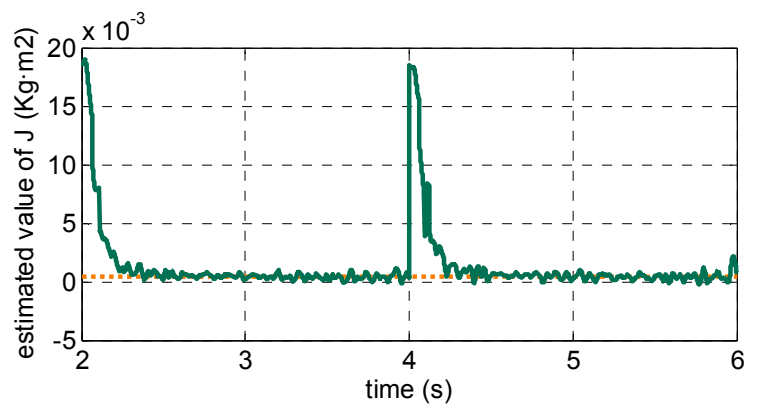

(c)

Figure 14. Experimental results under an acceleration of $\pm 420 \mathrm{rpm} / \mathrm{s}$ for $J_{0}=20 J$ : (a) Measured speed, (b) observed disturbance value for parameter mismatch error $\Delta J$; (c) estimated value of parameter $J$.

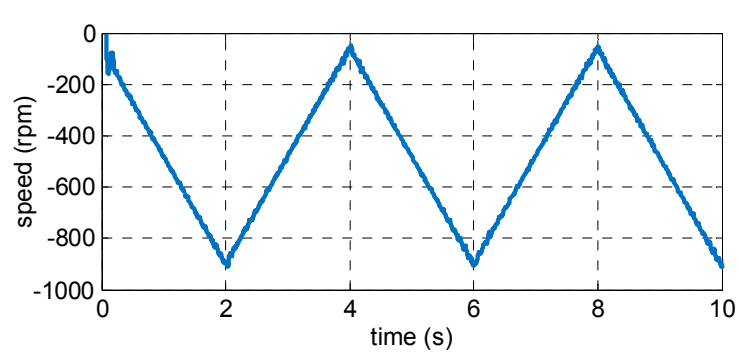

(a)

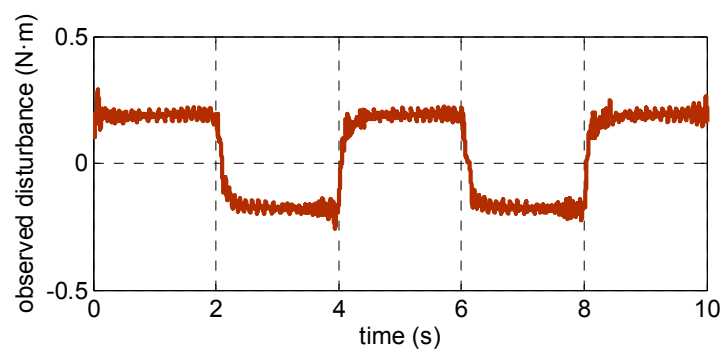

(b)

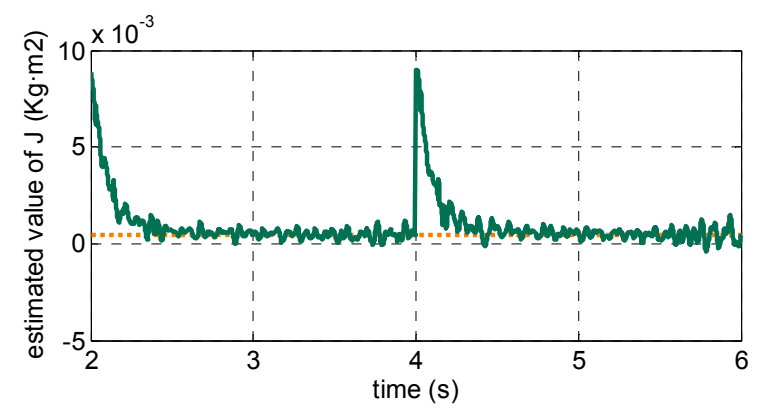

(c)

Figure 15. Experimental results under an acceleration of $\pm 420 \mathrm{rpm} / \mathrm{s}$ for $J_{0}=10 \mathrm{~J}$ : (a) Measured speed; (b) observed disturbance value for parameter mismatch error $\Delta J$; (c) estimated value of parameter $J$.

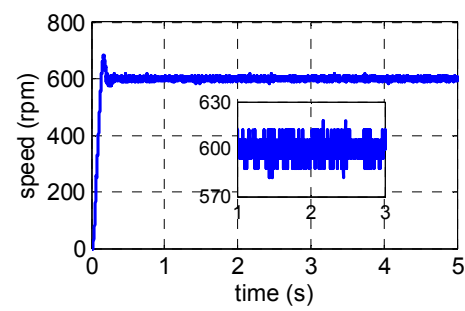

(a)

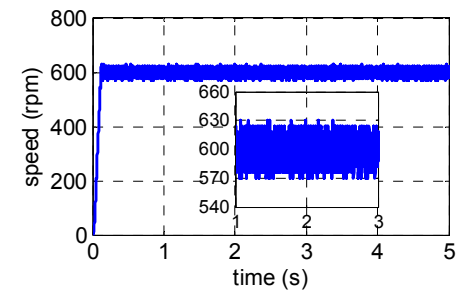

(b)

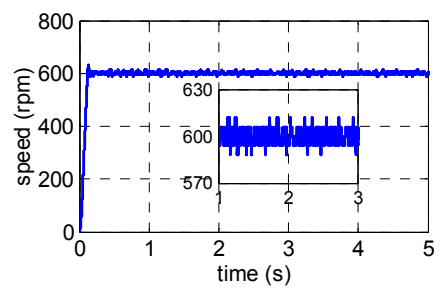

(c)

Figure 16. Experimental curves of rotor speed: (a) Under the PI method, (b) under the DMPC method with parameter mismatches by $B_{0}=4 B$ and $J_{0}=2 J$. (c) Under the DMPC and EMSO methods with the parameter estimated value. 


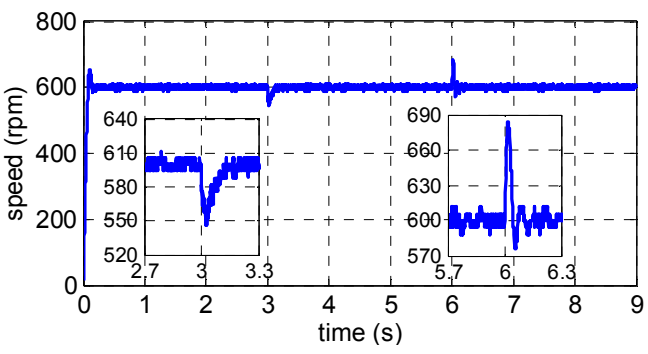

(a)

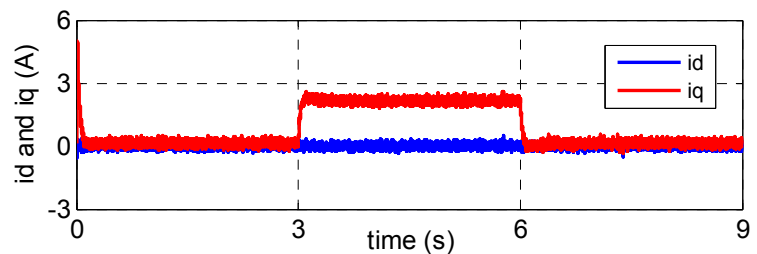

(b)

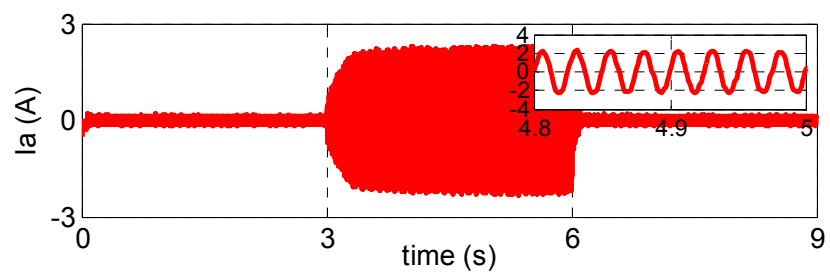

(c)

Figure 17. Experimental curves of rotor speed with a step disturbance of $1 \mathrm{~N} \cdot \mathrm{m}$ under the PI method: (a) Rotor speed responses; (b) curves of stator currents in the $d q$-axis; (c) curves of a-phase stator current.

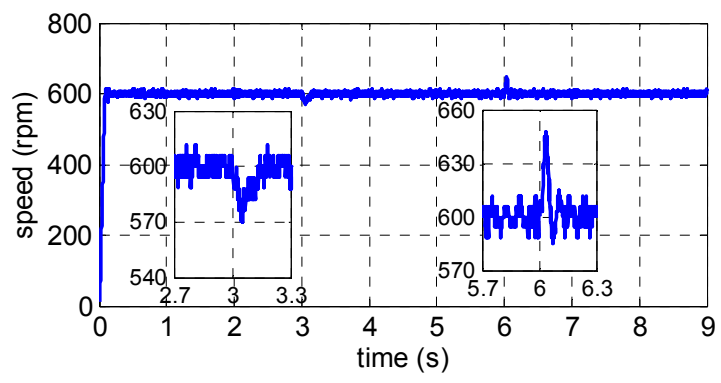

(a)

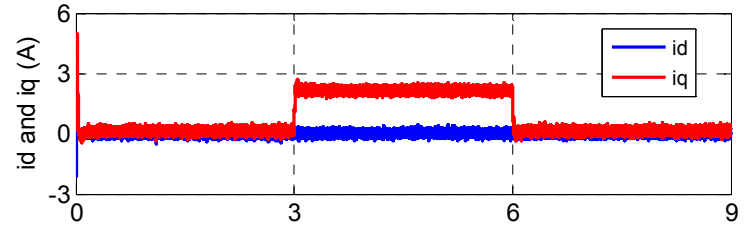

(b)

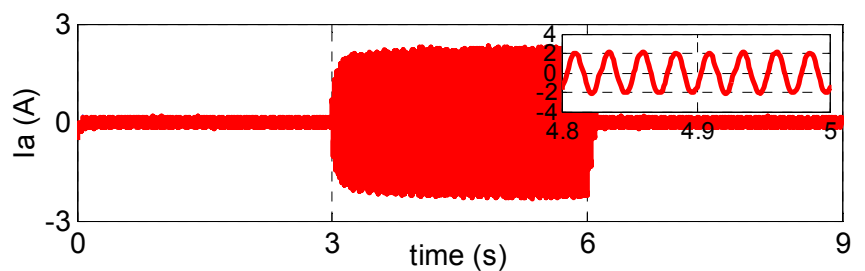

(c)

Figure 18. Experimental curves of rotor speed with a step disturbance of $1 \mathrm{~N} \cdot \mathrm{m}$ under the DMPC+ESMO method: (a) Rotor speed responses; (b) curves of stator currents in the $d q$-axis; (c) curves of a-phase stator current.

As shown in Figures 12-15, when the model parameters are mismatched, the estimated value $B$ can be made to converge to the real value by operating the motor at different stable speeds. The estimated value $J$ can be made to converge to the real value by operating the motor to track the different acceleration instructions.

After accurately estimating the mechanical model parameters, the state-space model can be obtained, and the proposed observer can be updated using the estimated parameters. An optimized DMPC with an ESMO can be established for the speed loop.

As shown in Figure 16a, to obtain a faster speed response, the PI method will produce an obvious overshoot in the rising phase. In Figure 16b,c, the DMPC method can achieve a faster speed response with a few overshoots. However, under parameter mismatches, the control performance of the DMPC method will be destroyed. As shown in Figure 16b, the DMPC controller is employed under the condition that the parameter is mismatched with $B_{0}=4 B$ and $J_{0}=2 J$. The DMPC method will 
have a large speed fluctuation near the given speed reference value. The more serious parameter mismatches will lead to greater speed fluctuations and even system instability. As shown in Figure 16c, by using the ESMO to estimate and update parameters, the DMPC+ ESMO method can achieve a better control effect.

As shown in Figure 17, the PI method after updating the parameters can achieve a faster response; however, it results in a significant speed fluctuation when the system is disturbed. To overcome the undesirable speed fluctuation due to the external disturbance, a higher proportional coefficient is required. This will cause a large overshoot in the rise phase. As shown in Figure 18, the DMPC+ESMO method can be employed in the speed loop after updating the parameters. The DMPC controller can achieve an optimal speed control with the optimal control action sequence, and the disturbance compensation technology with the ESMO is applied to improve the anti-disturbance ability and the robustness of the system. A comparison between Figures 17 and 18 shows that when the system loads the external disturbance, the maximum speed fluctuation under the PI method is $54 \mathrm{rpm}$, whereas the proposed DMPC with the ESMO reduces the maximum speed fluctuation to $24 \mathrm{rpm}$. The maximum speed fluctuation is reduced by $5 \%$. In Figure 19, the proposed ESMDO accurately and promptly estimates the external load disturbance.

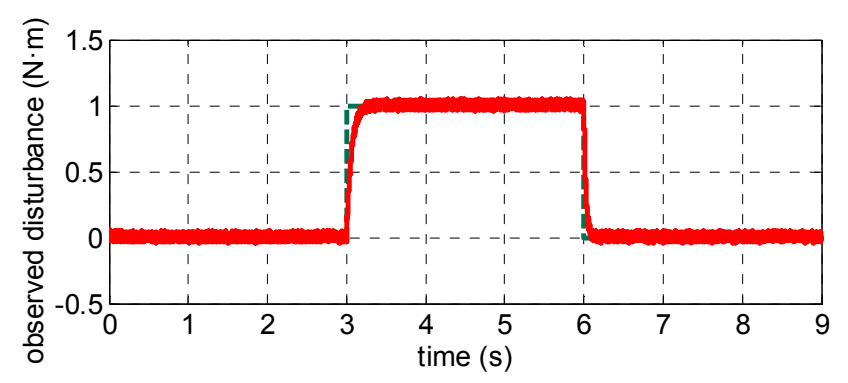

Figure 19. Experimental curves of observations based on the ESMO for a step disturbance of $1 \mathrm{~N} \cdot \mathrm{m}$.

\section{Conclusions}

In this study, a discrete model predictive controller with an extended sliding mode observer was developed for the speed control system of a PMSM to achieve an optimal speed controlin embedded systems and improve the disturbance rejection performance of the system. The designed controller enabled the system to attain a better dynamic response and reduce speed fluctuations. Moreover, the proposed ESMO could accurately identify the model parameters and the load disturbance of the system. The accurately obtained parameters could be used to update the DMPC, and the observed disturbance is immediately provided as feedback to the DMPC. The simulations and experimental results showed that the DMPC+ESMO method is effective for PMSM speed control systems, enabling better control performance and anti-disturbance ability.

Author Contributions: M.S., Y.D. and H.L. designed the proposed control strategy, M.S., Y.D. and Q.F. conducted experimental works, modeling and simulation, Y.D. and J.L. gave help of paper writing.

Funding: This work was supported in part by the National Natural Science Foundation of China (11603024).

Conflicts of Interest: The authors declare no conflict of interest.

\section{References}

1. Su, D.; Zhang, C.; Dong, Y. An Improved Continuous-Time Model Predictive Control of Permanent Magnetic Synchronous Motors for a Wide-Speed Range. Energies 2017, 10, 2051. [CrossRef]

2. Liu, J.; Li, H.; Deng, Y. Torque Ripple Minimization of PMSM Based on Robust ILC Via Adaptive Sliding Mode Control. IEEE Trans. Power Electron. 2018, 33, 3655-3671. [CrossRef]

3. Liu, X.; Zhang, C.; Li, K.; Zhang, Q. Robust current control-based generalized predictive control with sliding mode disturbance compensation for PMSM drives. ISA Trans. 2017, 71, 542-552. [CrossRef] [PubMed] 
4. Liu, Y.; Cheng, S.; Ning, B.; Li, Y. Robust model predictive control with simplified repetitive control for electrical machine drives. IEEE Trans. Power Electron. 2019, 34, 4524-4535. [CrossRef]

5. Qi, L.; Shi, H. Adaptive position tracking control of permanent magnet synchronous motor based on RBF fast terminal sliding mode control. Neurocomputing 2013, 115, 23-30. [CrossRef]

6. Li, S.; Liu, Z. Adaptive Speed Control for Permanent-Magnet Synchronous Motor System with Variations of Load Inertia. IEEE Trans. Ind. Electron. 2009, 56, 3050-3059. [CrossRef]

7. Yu, J.; Chen, B.; Yu, H.; Lin, C.; Ji, Z.; Cheng, X. Position tracking control for chaotic permanent magnet synchronous motors via indirect adaptive neural approximation. Neurocomputing 2015, 156, $245-251$. [CrossRef]

8. Kobayashi, H.; Katsura, S.; Ohnishi, K. An Analysis of Parameter Variations of Disturbance Observer for Motion Control. IEEE Trans. Ind. Electron. 2007, 54, 3413-3421. [CrossRef]

9. Wang, T.; Huang, J.; Ye, M.; Chen, J.; Kong, W.; Kang, M.; Yu, M. An EMF Observer for PMSM Sensorless Drives Adaptive to Stator Resistance and Rotor Flux-linkage. IEEE J. Emerg. Sel. Top. Power Electron. 2019, in press. [CrossRef]

10. Li, S.; Yang, J.; Chen, W.H.; Chen, X. Generalized Extended State Observer Based Control for Systems with Mismatched Uncertainties. IEEE Trans. Ind. Electron. 2012, 59, 4792-4802. [CrossRef]

11. Lin, F.J.; Sun, I.F.; Yang, K.J.; Chang, J.K. Recurrent Fuzzy Neural Cerebellar Model Articulation Network Fault-Tolerant Control of Six-Phase Permanent Magnet Synchronous Motor Position Servo Drive. IEEE Trans. Fuzzy Syst. 2016, 24, 153-167. [CrossRef]

12. Liu, H.; Li, S. Speed Control for PMSM Servo System Using Predictive Functional Control and Extended State Observer. IEEE Trans. Ind. Electron. 2012, 59, 1171-1183. [CrossRef]

13. Kouro, S.; Cortes, P.; Vargas, R.; Ammann, U.; Rodriguez, J. Model Predictive Control—A Simple and Powerful Method to Control Power Converters. IEEE Trans. Ind. Electron. 2009, 56, 1826-1838. [CrossRef]

14. Chai, S.; Wang, L.; Rogers, E. Model predictive control of a permanent magnet synchronous motor with experimental validation. Control Eng. Pract. 2013, 21, 1584-1593. [CrossRef]

15. Chai, S.; Wang, L.; Rogers, E. A Cascade MPC Control Structure for a PMSM With Speed Ripple Minimization. IEEE Trans. Ind. Electron. 2013, 60, 2978-2987. [CrossRef]

16. Belda, K.; Vosmik, D. Explicit Generalized Predictive Control of Speed and Position of PMSM Drives. IEEE Trans. Ind. Electron. 2016, 63, 3889-3896. [CrossRef]

17. Bolognani, S.; Bolognani, S.; Peretti, L.; Zigliotto, M. Design and Implementation of Model Predictive Control for Electrical Motor Drives. IEEE Trans. Ind. Electron. 2009, 56, 1925-1936. [CrossRef]

18. Hu, F.; Luo, D.; Luo, C.; Long, Z.; Wu, G. Cascaded Robust Fault-Tolerant Predictive Control for PMSM Drives. Energies 2018, 11, 3087. [CrossRef]

19. Wang, C.; Yang, M.; Zheng, W.; Long, J.; Xu, D. Vibration Suppression With Shaft Torque Limitation Using Explicit MPC-PI Switching Control in Elastic Drive Systems. IEEE Trans. Ind. Electron. 2015, 62, 6855-6867. [CrossRef]

20. Shoukry, Y.; El-Kharashi, M.W.; Hammad, S. MPC-On-Chip: An Embedded GPC Coprocessor for Automotive Active Suspension Systems. IEEE Embed. Syst. Lett. 2010, 2, 31-34. [CrossRef]

21. Song, Z.; Mei, X.; Jiang, G. Inertia identification based on model reference adaptive system with variable gain for AC servo systems. In Proceedings of the 2017 IEEE International Conference on Mechatronics and Automation (ICMA), Takamatsu, Japan, 6-9 August 2017; pp. 188-192. [CrossRef]

22. Dybkowski, M. Universal Speed and FluxEstimator for Induction Motor. Power Electron. Drives 2018, 38, 157-169. [CrossRef]

23. Liu, Z.; Yang, M.; Xu, D. A novel algorithm for on-line inertia identification via adaptive recursive least squares. In Proceedings of the IECON 2017-43rd Annual Conference of the IEEE Industrial Electronics Society, Beijing, China, 29 October-1 November 2017; pp. 2973-2978. [CrossRef]

24. Wang, K.; Chiasson, J.; Bodson, M.; Tolbert, L.M. A nonlinear least-squares approach for identification of the induction motor parameters. IEEE Trans. Autom. Control 2005, 50, 1622-1628. [CrossRef]

25. Hong, S.; Lee, C.; Borrelli, F.; Hedrick, J.K. A Novel Approach for Vehicle Inertial Parameter Identification Using a Dual Kalman Filter. IEEE Trans. Intell. Transp. Syst. 2015, 16, 151-161. [CrossRef]

26. Niu, L.; Xu, D.; Yang, M.; Gui, X.; Liu, Z. On-line Inertia Identification Algorithm for PI Parameters Optimization in Speed Loop. IEEE Trans. Power Electron. 2015, 30, 849-859. [CrossRef] 
27. Feng, Y.; Yu, X.; Han, F. High-Order Terminal Sliding-Mode Observer for Parameter Estimation of a Permanent-Magnet Synchronous Motor. IEEE Trans. Ind. Electron. 2013, 60, 4272-4280. [CrossRef]

28. Lian, C.; Xiao, F.; Gao, S.; Liu, J. Load Torque and Moment of Inertia Identification for Permanent Magnet Synchronous Motor Drives Based on Sliding Mode Observer. IEEE Trans. Power Electron. 2019, in press. [CrossRef]

29. Zhang, X.; Li, Z. Sliding-Mode Observer-Based Mechanical Parameter Estimation for Permanent Magnet Synchronous Motor. IEEE Trans. Power Electron. 2016, 31, 5732-5745. [CrossRef]

30. Xu, W.; Jiang, Y.; Mu, C. Novel Composite Sliding Mode Control for PMSM Drive System Based on Disturbance Observer. IEEE Trans. Appl. Supercond. 2016, 26, 1-5. [CrossRef]

31. Zhang, X.; Sun, L.; Zhao, K.; Sun, L. Nonlinear Speed Control for PMSM System Using Sliding-Mode Control and Disturbance Compensation Techniques. IEEE Trans. Power Electron. 2013, 28, 1358-1365. [CrossRef]

32. Lu, E.; Li, W.; Yang, X.; Xu, S. Composite Sliding Mode Control of a Permanent Magnet Direct-Driven System for a Mining Scraper Conveyor. IEEE Access 2017, 5, 22399-22408. [CrossRef]

33. Lyu, M.; Wu, G.; Luo, D.; Rong, F.; Huang, S. Robust Nonlinear Predictive Current Control Techniques for PMSM. Energies 2019, 12, 443. [CrossRef]

34. Chiu, C.S. Derivative and integral terminal sliding mode control for a class of MIMO nonlinear systems. Automatica 2012, 48, 316-326. [CrossRef]

35. Wang, A.; Jia, X.; Dong, S. A New Exponential Reaching Law of Sliding Mode Control to Improve Performance of Permanent Magnet Synchronous Motor. IEEE Trans. Magn. 2013, 49, 2409-2412. [CrossRef]

(C) 2019 by the authors. Licensee MDPI, Basel, Switzerland. This article is an open access article distributed under the terms and conditions of the Creative Commons Attribution (CC BY) license (http://creativecommons.org/licenses/by/4.0/). 